\title{
A Bibliografia entre o local e o global: perspectivas históricas e aplicadas
}

\author{
André Vieira de Freitas Araújo \\ Doutor; Universidade Federal do Rio de Janeiro, Rio de Janeiro, RJ, Brasil; \\ armarius.araujo@gmail.com \\ Giulia Crippa \\ Doutora; Universidade de Bolonha, Campus de Ravenna, Itália; \\ giulia.crippa2@unibo.it \\ Gustavo Silva Saldanha
}

Doutor; Instituto Brasileiro de Informação em Ciência e Tecnologia e Universidade Federal do Estado do Rio de Janeiro, Rio de Janeiro, RJ, Brasil; gustavosaldanha@ibict.br

Murilo Artur Araújo da Silveira

Doutor; Universidade Federal de Pernambuco, Recife, PE, Brasil; muriloas@gmail.com

O Fórum Internacional A Arte da Bibliografia, constituído em 2014, por pesquisadores de quatro instituições, a saber, Instituto Brasileiro de Informação em Ciência e Tecnologia (IBICT), Universidade Federal do Estado do Rio de Janeiro (UNIRIO), Universidade Federal do Rio de Janeiro (UFRJ) e Universidade de São Paulo (USP), atua desde então no formato "teia": agregando anualmente docentes, investigadores, profissionais e discentes em torno das questões bibliográficas.

Esta "teia" tem levado o Fórum a rever o foco do atual pensamento informacional, uma vez que a Bibliografia

[...] é a disciplina que, supervisionando todo o ciclo de comunicação registrada, além de reunir e organizar o universo de ferramentas existentes, estabelece as condições e protocolos que favorecem sistemas e métodos de mapeamento, arquivamento, pesquisa e recuperação de publicações passadas, presentes e em curso. (SERRAI, 2001, p. 13).

O conceito de "bibliografia", em sua amplitude histórico-social, une e multiplica as relações, de natureza teórica e aplicada, constituídas pelo Fórum Internacional A Arte da Bibliografia. 
O mais recente horizonte de integração desta "teia" está na Universidade Federal de Pernambuco (UFPE), responsável por sediar o $\mathrm{V}$ Seminário Internacional A Arte da Bibliografia, em 06 e 07 de dezembro de 2018, na cidade de Recife, nas dependências da Biblioteca Central da Universidade. O Seminário foi realizado pelo Programa de Pós-graduação em Ciência da Informação da Universidade Federal de Pernambuco (PPGCI-UFPE) com o seguinte tema: “A Bibliografia entre o local e o global: perspectivas históricas e aplicadas" (Figura 1). O evento contou com o apoio da Coordenação de Aperfeiçoamento de Pessoal de Nível Superior (CAPES), do Conselho Nacional de Desenvolvimento Científico e Tecnológico (CNPq), da Lerass (MICS Médiations en Information-Communication Spécialiseé, França), do Centro Interuniversitário de História das Ciências e da Tecnologia (CIUHCT/FCUL/FCT-UNL, Portugal) e do Programa de Pós-Graduação em Ciência da Informação da Universidade Federal de Minas Gerais (PPGCIUFMG).

Figura 1 - V Seminário Internacional A Arte da Bibliografia:

A Bibliografia entre o local e o global: perspectivas históricas e aplicadas (UFPE, 2018)

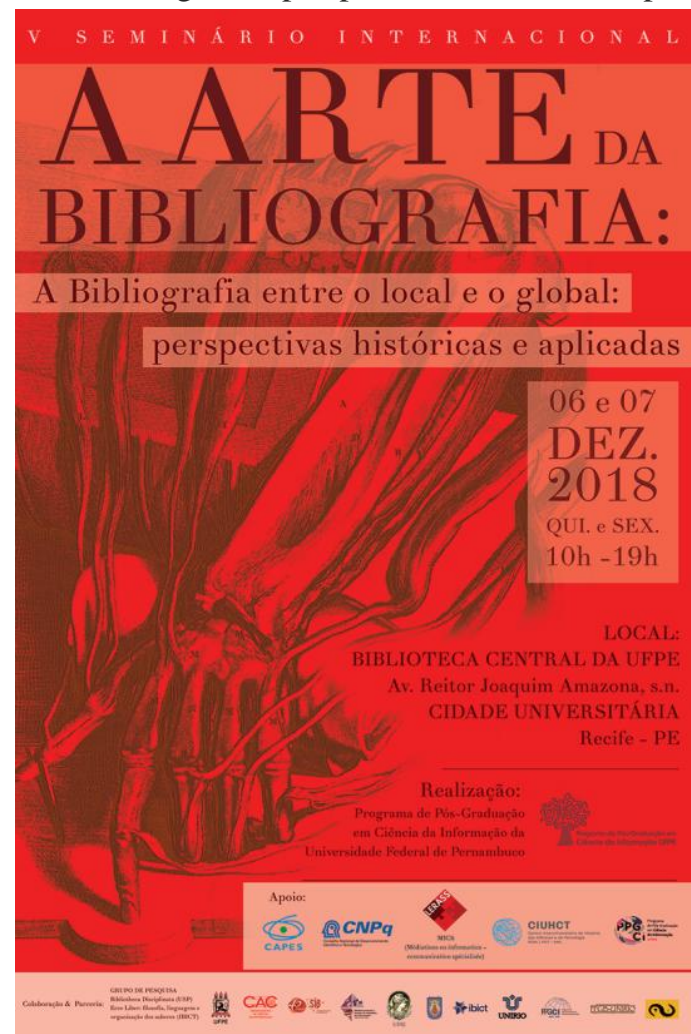

Fonte: Os Autores, 2018.

Arte: Rodrigo de Araújo, 2018. 
Sob a presidência de Giulia Crippa (ex-USP; atualmente Università di Bologna), o V Seminário Internacional A Arte da Bibliografia (2018) constituiu um momento de solidificação no percurso realizado nas edições anteriores, respectivamente no Rio de Janeiro (UFRJ, 2014), em São Paulo (USP, 2015), em Belo Horizonte (UFMG, 2016) e em Vitória (UFES, 2017). Ao mesmo tempo, a realização do Seminário em Pernambuco representou a primeira edição do evento fora do eixo Sudeste, o que demarcou a potência dos estudos bibliográficos na região e em outras geografias bibliográficas do país 1 .

É deste espaço-tempo que se constitui a base das problematizações empíricas e dos questionamentos teóricos e aplicados, fundados na condição bibliográfica da realidade social e desvelados no presente dossiê.

O evento, mais uma vez, mostrou o seu papel de destaque em prol da internacionalização da pesquisa e da interinstitucionalidade acadêmica e científica, a exemplo das referências estrangeiras, responsáveis pela conferência de abertura $^{2}$ (Viviane Couzinet, Université Toulouse III e Patrick Fraysse, Université Toulouse III) e pela conferência de encerramento (Luana Giurgevich, Centro Interuniversitário de História das Ciências e da Tecnologia - CIUHCT, Portugal).

Diversos docentes, estudantes, pesquisadores e bibliotecários que participaram do evento tiveram suas propostas avaliadas e selecionadas para serem aqui publicadas, incluindo aqueles que submeteram as suas propostas para comunicação oral ${ }^{3}$. Portanto, o evento vem traçando nesses anos um percurso de elaboração cada vez mais amplo e aprimorado, por entender que as pesquisas no domínio crescem e que necessitam ser apresentadas e discutidas em um fórum específico de debates.

O dossiê aqui reunido oferece um panorama consistente das discussões do V Seminário Internacional A Arte da Bibliografia que, graças ao generoso espaço oferecido pela Revista Em Questão, tem a possibilidade de alcançar um número cada vez maior de sujeitos que queiram se inteirar e participar desse "renascimento bibliográfico" em ato no Brasil.

Do ponto de vista da estrutura da proposta, três grandes dimensões sintetizam a ordenação temática, não mutuamente excludente, do dossiê: dimensão histórica e epistemológica, dimensão teórica e metodológica e 
dimensão interdisciplinar. Trata-se apenas de uma, dentre muitas outras, tentativa classificatória - típica da arte bibliográfica em fundamento e vivacidade - de reunir as transversais manifestações de pesquisas científicas que compõem o resultado final do conjunto de trabalhos aqui publicados.

No escopo histórico e epistemológico, encontramos como caracterização as relações entre bibliografia, bibliometria e política; a análise histórica da bibliografia no Brasil a partir do pensamento de Edson Nery da Fonseca e das encruzilhadas editoriais e acadêmicas até as margens do próprio Fórum Internacional A Arte da Bibliografia; os aportes da experiência bibliográfica pernambucana a partir dos anos 1960; as relações histórico-epistemológicas, a partir do ponto de vista francês, entre a cultura científico-praxiológica da bibliografia e sua condição no contexto da patrimonialização.

No universo teórico e metodológico, navegamos por uma rota entre os séculos XVI e XIX, a partir do debate historiográfico sobre a ilustração e a aplicação da arte da indicialização em Conrad Gesner e a construção do discurso sobre as biobibliografias segundo Gabriel Peignot. Do destino teóricometodológico, chegamos às fronteiras disciplinares: a dimensão interdisciplinar do dossiê discute Julius Otto Kaiser na relação entre Bibliografia e Documentação; retoma a questão do patrimônio sob a perspectiva do gesto entre Arquivologia e a episteme bibliográfica; revive a Bibliografia a partir de Paul Otlet e as condições contemporâneas da Biblioteca Digital Mundial; questiona a vivência bibliográfica no âmbito da cultura de convergência; investiga as relações entre a estrutura do livro na ordenação do conhecimento e mergulha no conceito de citação a partir da teoria cultural.

Por fim, das relações entre disciplinas, teorias e métodos, o horizonte aberto do atual dossiê da Arte da Bibliografia aborda a condição dos registros bibliográficos no contexto da web semântica, discute a história das bibliotecas eclesiásticas em Portugal a partir da discussão a aplicação de rigoroso método bibliográfico e se perde no labirinto das coleções, dos rastros de leitura e outros fragmentos bibliográficos do mudo social dos almanaques.

Como no meta-itinerário estabelecido pelo Fórum Internacional A Arte da Bibliografia entre 2014 e 2019, o presente quadro de pesquisas, fotografia de um tempo e sua resistência, representa uma espelharia da imaginação 
bibliográfica em seu constante indagar sobre uma realidade que insiste em avançar sob a pele sensível e insistente dos registros do conhecimento que se desenrolam sobre sua própria carne.

\section{Agradecimentos}

O Fórum Internacional A Arte da Bibliografia agradece aos profissionais, docentes e pesquisadores do Programa de Pós-graduação em Ciência da Informação e do Sistema Integrado de Bibliotecas da UFPE pela acolhida e colaboração na edição do evento.

\section{Referências}

SERRAI, A. Il cimento della Bibliografia. Milano: Sylvestre Bonnard, 2001.

${ }^{1}$ De característica itinerante, o Seminário Internacional A Arte da Bibliografia ocorrerá, em 2019, em Florianópolis. Esta edição, intitulada "VI Seminário Internacional A Arte da Bibliografia: das condições materiais e epistêmicas aos dilemas socioculturais", está sendo organizada e realizada pelo Fórum Internacional A Arte da Bibliografia, pelo Programa de PósGraduação em Gestão da Informação da Universidade do Estado de Santa Catarina (PPGInfoUDESC) e pelo Programa de Pós-Graduação em Ciência da Informação da Universidade Federal de Santa Catarina (PGCIN-UFSC). Para informações sobre o evento, ver: aartedabibliografia.org

${ }^{2}$ A Profa. Dra. Regina Marteleto (IBICT-UFRJ) também realizou a conferência de abertura.

${ }^{3}$ A edição de 2018 inaugurou a modalidade de submissão e comunicação de trabalhos. 